Published in final edited form as:

J Am Acad Orthop Surg. 2009 September ; 17(9): 591-600.

\title{
Treatment of Osteoarthritis of the Knee (Nonarthroplasty)
}

Dr. John Richmond, MD (Chair),

Chairman, Department of Orthopedic Surgery, New England Baptist Hospital, Boston, MA

Dr. David Hunter, MD, PhD,

Chief, Division of Research, New England Baptist Hospital

Dr. Jay Irrgang, PT, PhD, ATC,

Director of Clinical Research, Department of Orthopaedic Surgery, University of Pittsburgh,

Pittsburgh, PA

Dr. Morgan H. Jones, MD,

Associate, Department of Orthopaedic Surgery, and Director, Surgical Sports Medicine Research, Sports Health Center, Cleveland Clinic, Cleveland, $\mathrm{OH}$

Dr. Bruce Levy, MD,

Orthopaedic Surgeon, Departments of Orthopedic Surgery and Sports Medicine, Mayo Clinic,

Rochester, MN

Dr. Robert Marx, MD, MSc, FRCSC,

Orthopaedic Surgeon, Department of Orthopedic Surgery, Hospital for Special Surgery, New

York, NY, and Professor, Orthopedic Surgery, Weill Medical College, Cornell University, New

York

Dr. Lynn Snyder-Mackler, PT, ATC, SCS, ScD,

Physical Therapy Professor, Department of Physical Therapy, University of Delaware, Newark,

DE

Dr. William C. Watters III, MD,

Orthopaedic Surgeon, Bone and Joint Clinic of Houston, Houston, TX

Dr. Robert H. Haralson III, MD, MBA,

Executive Director of Medical Affairs, AAOS, Rosemont, IL

Dr. Charles M. Turkelson, PhD,

Director of Research and Scientific Affairs, AAOS

Ms. Janet L. Wies, MPH,

Manager, Clinical Practice Guidelines Unit, Research and Scientific Affairs Department, AAOS

Mr. Kevin M. Boyer,

Research Analyst, Guidelines, Research and Scientific Affairs Department, AAOS

Ms. Sara Anderson, MPH,

Research Analyst, Guidelines, Research and Scientific Affairs Department, AAOS

Mr. St. Justin St. Andre, MA,

At the time this guideline was being developed was Research Analyst, Guidelines, Research and Scientific Affairs Department, AAOS

Mr. Patrick Sluka, MPH, and

Research Analyst, Guidelines, Research and Scientific Affairs Department, AAOS

Mr. Richard McGowan, MLS

At the time this guideline was being developed was Medical Research Librarian, Research and

Scientific Affairs Department, AAOS 


\section{Abstract}

The clinical practice guideline was explicitly developed to include only treatments less invasive than knee replacement (ie, arthroplasty). Patients with symptomatic osteoarthritis of the knee are to be encouraged to participate in self-management educational programs and to engage in selfcare, as well as to lose weight and engage in exercise and quadriceps strengthening. The guideline recommends taping for short-term relief of pain as well as analgesics and intra-articular corticosteroids, but not glucosamine and/or chondroitin. Patients need not undergo needle lavage or arthroscopy with débridement or lavage. Patients may consider partial meniscectomy or loose body removal or realignment osteotomy, as conditions warrant. Use of a free-floating interpositional device should not be considered for symptomatic unicompartmental osteoarthritis of the knee. Lateral heel wedges should not be prescribed for patients with symptomatic medial compartmental osteoarthritis of the knee.

The work group was unable either to recommend or not recommend the use of braces with either valgus- or varus-directing forces for patients with medial unicompartmental osteoarthritis; the use of acupuncture or of hyaluronic acid; or osteotomy of the tibial tubercle for isolated symptomatic patellofemoral osteoarthritis.

\section{Overview and Rationale}

The clinical practice guideline was approved by the American Academy of Orthopaedic Surgeons (AAOS) on December 6,2008. It is based on a systematic review of published studies on the treatment of osteoarthritis (OA) of the knee in adults. The guideline was explicitly developed to include only treatments less invasive than knee replacement (ie, arthroplasty). In addition to providing practice recommendations, the guideline highlights gaps in the literature and areas that require future research.

The purpose of the clinical practice guideline is to help improve treatment based on current best evidence. Current evidence-based practice standards demand that physicians use the best available evidence in their clinical decision making. To assist physicians, the guideline consists of a series of systematic reviews of the available literature on the treatment of OA of the knee in adults. These systematic reviews were conducted between October 24, 2007, and February 22, 2008; they identify areas of good evidence, show where evidence is lacking, and indicate topics that future research must target to improve treatment. AAOS staff and the Osteoarthritis of the Knee work group systematically reviewed the available literature and subsequently wrote the recommendations based on a rigorous, standardized process.

Musculoskeletal care is provided in many different settings by many different providers. We created the guideline as an educational tool to guide qualified physicians through a series of treatment decisions in an effort to improve the quality and efficiency of care. The guideline should not be construed as including all proper methods of care or as excluding methods of care reasonably directed toward obtaining the same results. The ultimate judgment regarding any specific procedure or treatment must be made in light of all circumstances presented by the patient as well as the needs and resources particular to the locality or institution.

The clinical practice guideline resulted in 22 specific recommendations in 8 separate categories: lifestyle modifications, rehabilitation, mechanical interventions, alternative therapies, pain relievers, intra-articular injections, needle lavage, and surgery. Each recommendation is graded based on the total body of evidence available to recommend for or against the intervention, using the following system:

A. Good evidence (consistent level I studies). 
B. Fair evidence (consistent level II and III studies).

C. Poor-quality evidence (level IV or V).

Inconclusive: When there is insufficient or conflicting evidence.

Each recommendation was constructed using the following language, which takes into account the final grade of recommendation: recommended, A; suggested, B; option, C; neither recommended nor not recommended, Inconclusive.

\section{Potential Harms and Contraindications}

Individuals with $\mathrm{OA}$ of the knee often report joint pain, stiffness, and functional deficits. The goals of treatment are pain relief and improvement or maintenance of functional status. Long-term results were often not available, and adverse events varied by study (frequently they were not reported) in the literature available for the guideline. Most treatments are associated with some known risks, especially invasive and surgical treatments. In addition, contraindications vary widely based on the treatment administered. Therefore, discussion of available treatments and procedures applicable to the individual patient rely on mutual communication between the patient and physician, weighing the potential risks and benefits for that patient.

\section{Methods}

The methods used to develop the clinical practice guideline were designed to combat bias, enhance transparency, and promote reproducibility. Their purpose is both to give interested readers the ability to inspect all of the information the work group used to reach all of its decisions and to verify that these decisions are in accord with the best available evidence. The draft of the guideline was subject to peer review and public commentary. It was approved by the AAOS Evidence-Based Practice Committee, Guidelines and Technology Committee, Council on Research, Quality Assessment and Technology, and the Board of Directors. The methods used to prepare the guideline are detailed in the full clinical practice guideline, which is available at http://www.aaos.org/research/guidelines/OAKguideline.pdf.

Beyond the processes employed by the work group and the AAOS Guideline Unit in our own systematic review of the literature, the work group, to address certain questions, decided to utilize the evidence report "Treatment of Primary and Secondary Osteoarthritis of the Knee," prepared for the Agency for Healthcare Quality and Research (AHRQ), ${ }^{1}$ and the previously published Osteoarthritis Research Society International (OARSI) treatment guidelines, ${ }^{2,3}$ available at www.oarsi.org.

\section{Recommendations}

\section{Recommendation 1}

We suggest that patients with symptomatic OA of the knee be encouraged to participate in self-management educational programs, such as those conducted by the Arthritis Foundation, and incorporate activity modifications (eg, walking instead of running, alternative activities) into their lifestyle.

Level of Evidence: II

Grade of Recommendation: B

The OARSI guidelines, on which this recommendation is based, provide evidence from a single metaanalysis about the effect of education and self-management techniques 
(including changes in activity, exercise, and lifestyle modification) on patients with symptomatic OA of the knee. ${ }^{2,3}$ Self-management results in a statistically significant improvement in pain, although the clinical importance of this improvement cannot be determined. The effect is not large, but it is possible that, with such pain improvement distributed throughout a population, many patients might be shown to benefit from selfmanagement. Additionally, self-management is low in cost and has few associated harms. OARSI also reports that it was not possible to assess which specific aspects of selfmanagement programs were the most effective, ${ }^{3}$ thus making recommendation of a specific program difficult.

\section{Recommendation 2}

Regular contact to promote self-care is an option for patients with symptomatic OA of the knee.

Level of Evidence: IV

Grade of Recommendation: C

The OARSI guidelines provide evidence from a single randomized controlled trial (RCT) about the regular contact of patients with symptomatic OA of the knee. ${ }^{2,3}$ The AAOS work group initially considered the RCT evidence as being of a higher level but downgraded the evidence to level IV because the results that are relevant to this recommendation are from a post hoc subgroup analysis. The results of this subgroup analysis suggest that regular telephone contact significantly reduces the amount of pain experienced by patients. ${ }^{2,3}$ The evidence from OARSI suggests that this contact could be from lay personnel. Self-care is not defined in the OARSI document. The clinical significance of this finding cannot be determined because the minimally clinically important improvement (MCII) for the Arthritis Impact Measurement Scale (AIMS) instrument is unknown. The fact that telephone contact is of relatively low cost and has minimal, if any, associated harms supports this recommendation.

\section{Recommendation 3}

We recommend that patients with symptomatic OA of the knee who are overweight (BMI $>25$ ) should be encouraged to lose weight (a minimum of 5\% of body weight) and maintain their weight at a lower level with an appropriate program of dietary modification and exercise.

Level of Evidence: I

Grade of Recommendation: A

The OARSI guidelines provide evidence from two RCTs and a recent systematic review regarding the role of weight loss in patients with symptomatic OA of the knee. ${ }^{2,3}$ This evidence was evaluated as level I because the relevant studies were considered to be highquality, well-designed RCTs. Supporting this recommendation is that weight loss results in a possibly clinically important and statistically significant effect for functional improvement measured by the Western Ontario and McMaster Universities (WOMAC) function subscale $(0.69 ; 95 \% \mathrm{CI}, 0.24,1.14 ; \mathrm{MCII}=0.37))^{2,3}$ The effects of weight loss on other relevant outcomes are less clear. However, the effect of weight loss on functional improvement, combined with the fact that weight loss is likely to have health benefits that extend beyond $\mathrm{OA}$ of the knee, argues for this recommendation. 


\section{Recommendation 4}

We recommend that patients with symptomatic OA of the knee be encouraged to participate in low-impact aerobic fitness exercises.

Level of Evidence: I

Grade of Recommendation: A

The OARSI guidelines provide evidence from a systematic review that included 13 RCTs on aerobic exercises (eg, walking, cycling) in patients with OA of the knee. ${ }^{2,3}$ This recommendation was addressed by a systematic review of well-designed RCTs, making the evidence level I. The effect size of aerobic exercises on pain relief $(0.52 ; 95 \% \mathrm{CI}, 0.34$, $0.70)$ and disability $(0.46 ; 95 \% \mathrm{CI}, 0.25,0.67)^{2,3}$ are statistically significant. Although the clinical importance of these effects cannot be determined, the relatively low cost and likely additional health benefits support this recommendation.

\section{Recommendation 5}

Range-of-motion/flexibility exercises are an option for patients with symptomatic OA of the knee.

Level of Evidence: $\mathrm{V}$

Grade of Recommendation: C

Individuals with OA of the knee often suffer from joint stiffness and may have loss of joint motion and limited muscle flexibility. We found no published studies that address the effects of motion/flexibility exercises in patients with OA of the knee. Therefore, this recommendation is based on expert opinion, which is level $\mathrm{V}$ evidence. The consensus of the work group is that range-of-motion and flexibility exercises are an option to address these impairments. The low cost of these exercises, the limited harms associated with them, and their potential benefits warrant this recommendation.

\section{Recommendation 6}

We suggest quadriceps strengthening for patients with symptomatic OA of the knee.

Level of Evidence: II

Grade of Recommendation: B

This recommendation was addressed by one level II systematic review ${ }^{4}$ that included nine RCTs that examined the effects of quadriceps strengthening on pain ${ }^{5-13}$ and no RCTs that examined the effect of quadriceps strengthening on function. ${ }^{5-14}$ The systematic review concludes that quadriceps strengthening is effective. We supplemented the systematic review by performing our own meta-analyses. These analyses included an $\mathrm{RCT}^{15}$ not included in the systematic review.

The evidence is level II because not all of the included RCTs were high-quality, welldesigned trials. The systematic review ${ }^{4}$ that addressed this recommendation contained a metaanalysis that found that the effects of quadriceps strengthening on pain and function were statistically significant. The major shortcoming of this analysis is that it combined studies that measured pain and function in different ways, thus making it impossible to determine whether the effects were clinically important. The results of our own metaanalysis on pain and function suggest a statistically significant and possibly clinically 
important effect. In light of this, and in light of the lack of harms associated with quadriceps strengthening, the evidence is sufficient to suggest the use of quadriceps strengthening.

\section{Recommendation 7}

We suggest that patients with symptomatic OA of the knee use patellar taping for short-term relief of pain and improvement in function.

Level of Evidence: II

Grade of Recommendation: B

This recommendation of grade B is addressed by one level II systematic review ${ }^{16}$ that examined the use of patellar taping among patients with symptomatic OA of the knee. The review included one level I RCT ${ }^{17}$ and two level II RCTs. ${ }^{18,19}$ The RCTs in the systematic review report statistically significant and possibly clinically important effects of medial taping on pain (as measured by the visual analogue scale) immediately and 4 days after the start of taping. There is some evidence that medial taping reduces pain on movement by an amount that is possibly clinically important, but this effect is observed only when taping is compared with no taping, not when medial taping is compared with a sham.

\section{Recommendation 8}

We suggest that lateral heel wedges not be prescribed for patients with symptomatic medial compartmental OA of the knee.

Level of Evidence: II

Grade of Recommendation: B

This recommendation is addressed by one level II systematic review ${ }^{20}$ of three level II RCTs that examined the use of lateral heel wedges among patients with symptomatic medial compartmental OA of the knee The three level II RCTs were published in six separate articles. $^{21-26}$ Comparisons between lateral and neutral heel wedges are investigated, as are comparisons between lateral wedged insoles and lateral wedged insoles with subtalar strapping. The systematic review concludes that there is only limited evidence for the effectiveness of lateral heel wedges and related orthoses. In addition, the possibility exists that those who do not use them may experience fewer symptoms from OA of the knee.

\section{Recommendation 9}

We are unable to make a recommendation for or against the use of a brace with a valgusdirecting force for patients with medial unicompartmental OA of the knee.

Level of Evidence: II

Grade of Recommendation: Inconclusive

This recommendation of Inconclusive is addressed by one level II systematic review ${ }^{20}$ of two RCTs ${ }^{27,28}$ that examined the use of braces among patients with medial unicompartmental OA of the knee. The brace is applied with the intent of altering a varus malaligned knee by moving the alignment of the knee in a valgus direction. One of the $\mathrm{RCTs}^{28}$ included in the systematic review presented insufficient quantitative data for analyses. The qualitative results reported by the systematic review (for the study that did not adequately report quantitative data) indicate that patients in the brace group improved more on each outcome than did patients who received either a neoprene sleeve or were in the 
control group. The systematic review concludes that there is only limited evidence for the effectiveness of knee braces.

\section{Recommendation 10}

We are unable to make a recommendation for or against the use of a brace with a varusdirecting force for patients with lateral unicompartmental OA of the knee.

Level of Evidence: $\mathrm{V}$

Grade of Recommendation: Inconclusive

A knee brace applied with the intent of altering a valgus malaligned knee by moving the alignment of the knee in a varus direction has been proposed as a treatment of individuals with symptomatic lateral tibiofemoral OA of the knee. No studies were identified by our systematic review processes specific to patients with lateral tibiofemoral OA of the knee. Because of the absence of studies to address this treatment, this recommendation is level V.

\section{Recommendation 11}

We are unable to make a recommendation for or against the use of acupuncture as an adjunctive therapy for pain in patients with symptomatic OA of the knee.

Level of Evidence: I

Grade of Recommendation: Inconclusive

This recommendation is addressed by the OARSI guidelines and by six level I and eight level II RCTs. The OARSI guidelines report conflicting evidence from two RCTs and one systematic review regarding the symptomatic benefit of acupuncture in patients with OA of the knee. ${ }^{2,3}$ One $\mathrm{RCT}^{29}$ and the systematic review ${ }^{30}$ support the use of acupuncture; one $\mathrm{RCT}^{31}$ does not. In an attempt to resolve these conflicting results, we conducted a de novo systematic review of previously published systematic reviews and confirmed that their conclusions were conflicting. Consequently, we updated these reviews with our own, including performing a meta-analysis of the results of all eligible RCTs on the use of acupuncture in patients with symptomatic OA of the knee.

Our meta-analysis suggests that the reported effects of acupuncture on pain depend on study design and conduct. Accordingly, the largest effects on pain and function are found in studies that did not employ blinding; the smallest effects are found in studies that employed blinding and verified that patients were blinded; and intermediate effects are found in studies that employed blinding but did not verify that patients were blinded. Further analyses showed that the effects of acupuncture on pain and function were not statistically significant in studies that verified that their patients were blinded. However, there remains a large amount of unexplained variance in this group of studies as well as in the other two groups. Thus, although our meta-analytic results suggest that the apparent effects of acupuncture are to the result of a placebo effect, the unexplained differences among study results do not conclusively prove this point. Because of this, and because of the conflicting conclusions of previously published systematic reviews, we agreed that currently available evidence about the benefits of acupuncture is inconclusive.

\section{Recommendation 12}

We recommend that glucosamine and/or chondroitin sulfate or hydrochloride not be prescribed for patients with symptomatic OA of the knee. 
Level of Evidence: I

Grade of Recommendation: A

This recommendation is based on an AHRQ report that provides evidence from one RCT and six systematic reviews on the use of glucosamine and/or chondroitin sulfate or hydrochloride among patients with symptomatic OA of the knee. ${ }^{1}$ We evaluated this evidence as level I. The AHRQ report states that "the best available evidence found that glucosamine hydrochloride, chondroitin sulfate, or their combination did not have any clinical benefit in patients with primary OA of the knee."1 One of the six systematic reviews concluded no clinical benefit for glucosamine or chondroitin compared with placebo. The remaining five systematic reviews did not provide conclusions on the clinical importance; however, they did conclude glucosamine and/or chondroitin are superior to placebo. The AAOS work group agreed that the AHRQ report presents a high-quality systematic review of level I evidence demonstrating that the best available evidence does not support the prescribing of glucosamine and/or chondroitin.

\section{Recommendation 13}

We suggest that patients with symptomatic OA of the knee receive one of the following analgesics for pain unless there are contraindications to this treatment: acetaminophen $(\leq 4 \mathrm{~g} /$ day) or nonsteroidal anti-inflammatory drugs (NSAIDs).

Level of Evidence: II

Grade of Recommendation: B

The OARSI guidelines provide evidence from three systematic reviews on the use of acetaminophen compared with placebo among patients with symptomatic OA of the knee., ${ }^{2,3}$ In addition, the OARSI guidelines provide evidence from four systematic reviews that examined the use of NSAIDs compared with placebo or acetaminophen. We categorized this evidence as level II because of the lesser quality of included trials in the systematic reviews.

The evidence suggests that, compared with placebo, there are statistically significant effects of acetaminophen on pain relief without any statistically significant risk of toxicity. The clinical importance of the effect on pain cannot be determined. NSAIDs appear to have a statistically significant effect on pain, the clinical importance of which cannot be determined. NSAIDs also appear to reduce pain significantly more than does acetaminophen, but the effect is not clinically important. Finally, NSAIDs have statistically significant and favorable effects on clinical response and patient preference compared with acetaminophen, but they also have a statistically significant increased risk of gastrointestinal (GI) complications. The clinical importance of these effects cannot be determined.

\section{Recommendation 14}

We suggest that patients with symptomatic OA of the knee and increased GI risk (ie, age $\geq 60$ years, comorbid medical conditions, history of peptic ulcer disease, history of GI bleeding, concurrent use of corticosteroids and/or concomitant use of anticoagulants) receive one of the following analgesics for pain: acetaminophen (not to exceed $4 \mathrm{~g}$ per day), topical NSAIDs, nonselective oral NSAIDs plus gastroprotective agent; or cyclooxygenase-2 (COX-2) inhibitors.

Level of Evidence: II

Grade of Recommendation: B 
The OARSI guidelines provide evidence from 11 systematic reviews on the use of acetaminophen, topical NSAIDs, nonselective oral NSAIDs plus a gastroprotecive agent, or COX-2 inhibitors among patients with symptomatic OA of the knee who have increased risk of GI complications. ${ }^{2,3}$ This evidence was evaluated as level II because of the lesser quality of included trials in the systematic reviews. The effectiveness of acetaminophen is discussed in the previous recommendation. For topical NSAIDs, the evidence suggests that there is a statistically significant effect on pain relief, stiffness, and function; however, the clinical importance of these effects cannot be determined. The effectiveness of nonselective oral NSAIDs and COX-2 inhibitors is also discussed in the previous recommendation. The evidence for oral NSAIDs included trials that investigated nonselective oral NSAIDs as well as COX-2 inhibitors. Each of these regimens has a reduced relative risk for adverse GI events compared with the isolated use of oral NSAIDs. The evidence does not demonstrate an advantage for any of these treatment regimens. ${ }^{2,3}$

\section{Recommendation 15}

We suggest that intra-articular corticosteroids be used for short-term pain relief for patients with symptomatic $\mathrm{OA}$ of the knee.

\section{Level of Evidence: II}

Grade of Recommendation: B

Intra-articular corticosteroid treatment in patients with symptomatic OA of the knee was examined in three level systematic reviews, ${ }^{32-34}$ which include lesser quality RCTs. A total of unique RCTs that compared corticosteroid and placebo interventions were included in these reviews. ${ }^{35-46}$ All three of the systematic reviews conclude that intra-articular corticosteroids are effective for relieving pain in the short term (at 1 week and 16-24 weeks, ${ }^{34}$ at 1 week and continuing at 2 to 3 weeks, ${ }^{32}$ and within 1 to 2 weeks ${ }^{33}$ ). The only systematic review that commented on whether these effects were clinically important concluded that the effects on pain at 1 to 2 weeks were not. ${ }^{33}$ However, we were able to evaluate clinical importance using data from another systematic review, ${ }^{32}$ which suggested that clinically important and statistically significant effects of intra-articular corticosteroids on pain (as measured by the visual analogue scale) exist at 1 week after injection. There is little evidence suggesting that intra-articular corticosteroids have longer-term benefits.

\section{Recommendation 16}

We cannot make a recommendation for or against the use of intra-articular hyaluronic acid for patients with mild to moderate symptomatic OA of the knee.

Levels of Evidence: I and II

Grade of Recommendation: Inconclusive

The AHRQ report ${ }^{1}$ provides evidence from 42 trials that examined the effectiveness of intraarticular hyaluronic acid (ie, viscosupplementation) in patients with symptomatic OA. The AHRQ report explains that six meta-analyses and one additional RCT were considered in their review. This evidence was evaluated as levels I and II because some of the trials included in the AHRQ report were not well-designed, high-quality RCTs. The AHRQ report states that "visco-supplementation generally shows positive effects." "However, the AHRQ report further notes that these results could have been influenced by "trial quality, potential publication bias, and unclear clinical significance (importance)." "The AHRQ report also noted that the "pooled effects from poor-quality trials were as much as twice those obtained from higher ones (trials)."1 The AAOS work group agreed that the AHRQ report presents a 
high-quality systematic review of level I and level II evidence and graded this recommendation as inconclusive because of the conflicting evidence in pooled effects along with the unclear clinical importance of the results.

\section{Recommendation 17}

We suggest that needle lavage not be used for patients with symptomatic OA of the knee.

Levels of Evidence: I and II

Grade of Recommendation: B

The AAOS conducted a systematic review that identified one level I RCT ${ }^{47}$ and three level II RCTs ${ }^{48-50}$ that studied needle lavage in patients with symptomatic OA of the knee. All three level II RCTs were graded as such because of lack of patient and caregiver blinding and failure to conceal the allocation of patients to treatment groups. Of all outcomes in all of the studies, only one was statistically significant at 12 or 24 weeks after needle lavage: quality of well-being at 24 weeks. In general, longer-term effects also were not statistically significant. Because of the lack of demonstrated effect of needle lavage, we suggest that it not be used.

\section{Recommendation 18}

We recommend against performing arthroscopy with débridement or lavage in patients with a primary diagnosis of symptomatic OA of the knee.

Levels of Evidence: I and II

Grade of Recommendation: A

One level II systematic review ${ }^{51}$ containing three $\mathrm{RCTs}^{48,52,53}$ examined the use of arthroscopic débridement in patients with symptomatic OA of the knee. The sole level I $\mathrm{RCT}^{53}$ included comparison of arthroscopic lavage alone to sham arthroscopic surgery (placebo). Two additional level II RCTs ${ }^{35,54}$ investigated the differences between arthroscopic lavage alone and placebo. The systematic review concluded that "[arthroscopic débridement] has no significant benefit for knee OA of undiscriminated cause." ${ }^{1}$

In the level I RCT, the effects of arthroscopy with débridement or lavage were not statistically significant in the great majority of patient-oriented outcome measures for pain and function at multiple time points from 1 week to 2 years after surgery. ${ }^{53}$ There may be limited applicability of the level I RCT, which is called into question because of its limited population (largely older male and veteran) and the number of potential study participants who declined randomization into a treatment group. However, additional evidence from the systematic review and the other RCTs we examined also support the lack of incremental benefit of arthroscopic débridement or lavage. In addition, surgical treatment subjects the patient to potentially increased risks (eg, anesthetic complications, infection, thrombophlebitis). None of the evidence we examined specifically included patients who had a primary diagnosis of meniscal tear, loose body, or other mechanical derangement and who also had a concomitant diagnosis of OA of the knee, and the present recommendation does not apply to such patients.

\section{Recommendation 19}

Arthroscopic partial meniscectomy or loose body removal is an option in patients with symptomatic OA of the knee who also have primary signs and symptoms of a torn meniscus and/or a loose body. 
Level of Evidence: $\mathrm{V}$

Grade of Recommendation: C

Currently, arthroscopic partial meniscectomy and/or loose body removal is routinely performed in patients with symptomatic OA of the knee who also have primary signs and symptoms of a torn meniscus and/or a loose body. No level I or II evidence is available to suggest that arthroscopic partial meniscectomy and/or loose body removal is or is not appropriate for a patient with a primary diagnosis of a torn meniscus and/or a loose body in whom OA of the knee is identified secondarily. The expert opinion consensus (level V evidence) of the AAOS work group is that arthroscopic partial meniscectomy or loose body removal is an option for patients with primary signs and symptoms of a torn meniscus and/or loose body. Additional studies are warranted to look at the outcomes of arthroscopic surgery in this population.

\section{Recommendation 20}

We cannot make a recommendation for or against an osteotomy of the tibial tubercle for patients with isolated symptomatic patellofemoral osteoarthritis.

Level of Evidence: $\mathrm{V}$

Grade of Recommendation: Inconclusive

No studies investigating osteotomy of the tibial tubercle for patients with isolated patellofemoral OA were identified by our systematic literature searches, thus making this recommendation that of expert opinion, level V. Osteotomy of the tibial tubercle has been proposed as a treatment of patients with isolated symptomatic patellofemoral OA of the knee.

\section{Recommendation 21}

Realignment osteotomy is an option in active patients with symptomatic unicompartmental OA of the knee with malalignment.

Levels of Evidence: IV and V

Grade of Recommendation: C

A systematic review investigated realignment osteotomy in patients with unicompartmental knee OA with malalignment. ${ }^{55}$ This review examined various osteotomy surgical techniques but did not specifically address the efficacy of realignment osteotomy. Rather, it compared various realignment osteotomy surgical techniques and concluded that there is limited evidence for the efficacy of osteotomy. To address efficacy, we examined five case series studies $^{56-60}$ and the baseline and follow-up measurements within each treatment arm of six RCTs, ${ }^{61-66}$ comparing different surgical techniques. This evidence, including the preoperative and postoperative data from RCTs, is considered to be level IV evidence because there is no comparison to a placebo or control group. The AAOS work group agreed that the level IV case series evidence suggested that realignment osteotomy had benefits that lasted up to 2 years after surgery. We did not analyze longer-term results because of loss of patients in the relevant studies. Additionally, using level V expert opinion, the work group qualified this recommendation for "active" patients. 


\section{Recommendation 22}

We suggest not using a free-floating interpositional device for patients with symptomatic unicompartmental OA of the knee.

Levels of Evidence: IV

Grade of Recommendation: B

Evidence from one published case series ${ }^{67}$ and from the Australian Orthopaedic Association National Joint Replacement Registry, ${ }^{68-70}$ reporting the results of free-floating interpositional device surgeries performed between 2004 and 2006, addresses the use of free-floating interpositional devices for treatment of unicompartmental OA of the knee. We categorized this evidence as level IV evidence. In 2007, the Australian registry stated that it no longer uses free-floating interpositional devices. ${ }^{71}$ The evidence demonstrates high secondary surgery rates in the patients followed in both series. Revision to total knee arthroplasty ranged from $32 \%$ at 2 years to $62 \%$ at 3 years. The AAOS work group upgraded this recommendation to grade $\mathrm{B}$, based on the high revision rates in these series and the potential harm associated with this intervention.

\section{Future Research}

Many treatments of OA of the knee are addressed by randomized controlled trials. The quality of these trials is, in some cases, questionable. To achieve a high-quality literature base, academic authors and scientists should invest their time and effort into studies designed to avoid bias. Techniques to limit bias include proper randomization and adequate, verified blinding of investigators, patients, and/or evaluators wherever possible. Future studies should also include a priori power analysis to ensure clinical improvement that matters to the patient. These studies should use patient-oriented outcome measures (eg, WOMAC, Medical Outcomes Study 12-Item Short Form) whose key psychometric characteristics have been evaluated and validated. The use of validated patient-oriented outcome measures will ensure that the measure of success of future studies is determined by minimal clinically important improvements.

High-quality evidence for surgical treatment (up to but not including knee arthroplasty) of $\mathrm{OA}$ of the knee is generally lacking. The logistical difficulties and ethical concerns in conducting placebo-controlled studies of surgical interventions compromise the quality of these studies. To improve the quality of future studies of surgical treatments, the use of active, nonplacebo control groups should be considered. Surgical treatment of OA of the knee is often indicated in patients who exhibit symptoms unique from those of other pathologies (ie, loose body, meniscal tear) in addition to the symptoms from OA of the knee. Surgical treatment is also often indicated in patients with specific characteristics (ie, age, activity level, severity of OA). Investigators should develop rigorous patient-inclusion criteria to ensure that patients who typically receive the surgical intervention in clinical practice are adequately represented in the study population.

\section{Biography}

Dr. Richmond or a member of his immediate family serves as a board member, owner, officer, or committee member of Arthroscopy Association of North America, American Orthopaedic Society for Sports Medicine, American Academy of Orthopaedic Surgeons, Eastern Orthopaedic Association, and New England Baptist Hospital; serves as a paid consultant to or is an employee of Lifenet, Mitek, Stryker, Serica, and Wyeth; has received research or institutional support from Arthrex, DJ Orthopaedics, and Smith \& Nephew; and 
has stock or stock options held in Serica. Dr. Hunter or a member of his immediate family has received research or institutional support from DJ Orthopaedics, Eli Lilly, Merck, Pfizer, Stryker, Wyeth, AstraZeneca, and NIH. Dr. Irrgang or a member of his immediate family serves as a board member, owner, officer, or committee member of Orthopaedic Section, American Physical Therapy Association, and has received research or institutional support from Biomet, DePuy, Smith \& Nephew, Stryker, and Synthes. Dr. Jones or a member of his immediate family has received research or institutional support from Biomimetic, DePuy, Regen Biologies, Small Bone Innovations, Stryker, TissueLink, ARS Arthro AG, Diapedia LLC, King Pharmacy, Arthrosurface, and Apopharma. Dr. Levy or a member of his immediate family serves as a paid consultant to or is an employee of Valpo Orthotec. Dr. Watters or a member of his immediate family serves as a board member, owner, officer, or committee member of Bone and Joint Decade, USA, North American Spine Society, Intrinsic Therapeutics, Work Loss Data Institute, and American Board of Spine Surgery; serves as a paid consultant to or is an employee of Blackstone Medical, Medtronic Sofamor Danek, Stryker, Instrinsic Therapeutics, and McKessen Health Care Solutions; and has stock or stock options held in Intrinsic Therapeutics. Dr. Haralson or a member of his immediate family serves as a paid consultant to or is an employee of Medtronic and Medtronic Sofamor Danek, and has stock or stock options held in Orthofix and Allmeds. Ms. Wies or a member of her immediate family has stock or stock options held in Shering Plough. None of the following authors or a member of their immediate families has received anything of value from or owns stock in a commercial company or institution related directly or indirectly to the subject of this article: Dr. Marx, Dr. Snyder-Mackler, Dr. Turkelson, Mr. Boyer, Ms. Anderson, Mr. St. Andre, Mr. Sluka, and Mr. McGowan.

\section{References}

1. Samson, DJ.; Grant, MD.; Ratko, TA.; Bunnell, CJ.; Zieglcr, KM.; Aronson, N. Treatment of Primary and Secondary Osteoarthritis of the Knee. Rockville, MD: Agency for Healthcare Research and Quality; 2007 Sep 1. Report No. 157

2. Zhang W, Moskowitz RW, Nuki G, et al. OARSI recommendations for the management of hip and knee osteoarthritis: Part 1. Critical appraisal of existing treatment guidelines and systematic review of current research evidence. Osteoarthritis Cartilage. 2007; 15:981-1000. [PubMed: 17719803]

3. Zhang W, Moskowitz RW, Nuki G, et al. OARSI recommendations for the management of hip and knee osteoarthritis: Part II. OARSI evidence-based, expert consensus guidelines. Osteoarthritis Cartilage. 2008; 16:137-162. [PubMed: 18279766]

4. Roddy E, Zhang W, Doherty M. Aerobic walking or strengthening exercise for osteoarthritis of the knee? A systematic review. Ann Rheum Dis. 2005; 64:544-548. [PubMed: 15769914]

5. Fransen M, Crosbie J, Edmonds J. Physical therapy is effective for patients with osteoarthritis of the knee: A randomized controlled clinical trial. J Rheumatol. 2001; 28:156-164. [PubMed: 11196518]

6. Topp R, Woolley S, Hornyak J III, Khuder S, Kahaleh B. The effect of dynamic versus isometric resistance training on pain and functioning among adults with osteoarthritis of the knee. Arch Phys Med Rehabil. 2002; 83:1187-1195. [PubMed: 12235596]

7. Baker KR, Nelson ME, Felson DT, Layne JE, Sarno R, Roubenoff R. The efficacy of home based progressive strength training in older adults with knee osteoarthritis: A randomized controlled trial. J Rheumatol. 2001; 28:1655-1665. [PubMed: 11469475]

8. O'Reilly SC, Muir KR, Doherty M. Effectiveness of home exercise on pain and disability from osteoarthritis of the knee: A randomised controlled trial. Ann Rheum Dis. 1999; 58:15-19. [PubMed: 10343535]

9. Thomas KS, Muir KR, Doherty M, Jones AC, O'Reilly SC, Bassey EJ. Home based exercise programme for knee pain and knee osteoarthritis: Randomised controlled trial. BMJ. 2002; 325:752. [PubMed: 12364304]

10. Hopman-Rock M, Westhoff MH. The effects of a health educational and exercise program for older adults with osteoarthritis for the hip or knee. J Rheumatol. 2000; 27:1947-1954. [PubMed: 10955337] 
11. van Baar ME, Dekker J, Oostendorp RA, et al. The effectiveness of exercise therapy in patients with osteoarthritis of the hip or knee: A randomized clinical trial. J Rheumatol. 1998; 25:24322439. [PubMed: 9858441]

12. Quilty B, Tucker M, Campbell R, Dieppe P. Physiotherapy, including quadriceps exercises and patellar taping, for knee osteoarthritis with predominant patello-femoral joint involvement: Randomized controlled trial. J Rheumatol. 2003; 30:1311-1317. [PubMed: 12784408]

13. Ettinger WH, Burns R, Messier SP, et al. A randomized trial comparing aerobic exercise and resistance exercise with a health education program in older adults with knee osteoarthritis. The Fitness and Seniors Trial (FAST). JAMA. 1997; 277:25-31. [PubMed: 8980206]

14. Petrella RJ, Bartha C. Home based exercise therapy for older patients with knee osteoarthritis: A randomized clinical trial. J Rheumatol. 2000; 27:2215-2221. [PubMed: 10990236]

15. Maurer BT, Stern AG, Kinossian B, Cook KD, Schumacher HR Jr. Osteoarthritis of the knee: Isokinetic quadriceps exercise versus an educational intervention. Arch Phys Med Rehahil. 1999; 80:1293-1299.

16. Warden SJ, Hinman RS, Watson MA Jr, Avin KG, Bialocerkowski AE, Crossley KM. Patellar taping and bracing for the treatment of chronic knee pain: A systematic review and meta-analysis. Arthritis Rheum. 2008; 59:73-83. [PubMed: 18163413]

17. Hinman RS, Bennell KL, Crossley KM, McConnell J. Immediate effects of adhesive tape on pain and disability in individuals with knee osteoarthritis. Rheumatology (Oxford). 2003; 42:865-869. [PubMed: 12730546]

18. Cushnaghan J, McCarthy C, Dieppe P. Taping the patella medially: A new treatment for osteoarthritis of the knee joint? BMJ. 1994; 308:753-755. [PubMed: 8142829]

19. Hinman RS, Crossley KM, McConnell J, Bennell KL. Efficacy of knee tape in the management of osteoarthritis of the knee: Blinded randomised controlled trial. BMJ. 2003; 327:135. [PubMed: 12869456]

20. Brouwer RW, Jakma TS, Verhagen AP, Verhaar JA, Bierma-Zeinstra SM. Braces and orthoses for treating osteoarthritis of the knee. Cochrane Database Syst Rev. 2005; 1:CD004020. [PubMed: 15674927]

21. Maillefert JF, Hudry C, Baron G, et al. Laterally elevated wedged insoles in the treatment of medial knee osteoarthritis: A prospective randomized controlled study. Osteoarthritis Cartilage. 2001; 9:738-745. [PubMed: 11795993]

22. Pham T, Maillefert JF, Hudry C, et al. Laterally elevated wedged insoles in the treatment of medial knee osteoarthritis: A two-year prospective randomized controlled study. Osteoarthritis Cartilage. 2004; 12:46-55. [PubMed: 14697682]

23. Toda Y, Segal N. Usefulness of an insole with subtalar strapping for analgesia in patients with medial compartment osteoarthritis of the knee. Arthritis Rheum. 2002; 47:468-473. [PubMed: 12382293]

24. Toda Y, Segal N, Kato A, Yamamoto S, Irie M. Effect of a novel insole on the subtalar joint of patients with medial compartment osteoarthritis of the knee. J Rheumatol. 2001; 28:2705-2710. [PubMed: 11764221]

25. Toda Y, Tsukimura N. A six month follow-up of a randomized trial comparing the efficiency of a lateral-wedge insole with subtabalar strapping and in-shoe lateral wedge insole in patients with varus deformity osteoarthritis of the knee. Arthritis Rheum. 2004; 50:3129-3136. [PubMed: 15476225]

26. Toda Y, Tsukimura N. A 2-year follow-up of a study to compare the efficiency of lateral wedged insoles with subtalar strapping and in-shoe lateral wedged insoles in patients with varus deformity osteoarthritis of the knee. Osteoarthritis Cartilage. 2006; 14:231-237. [PubMed: 16271485]

27. Brouwer RW, van Raaij TM, Verhaar JA, Coene LN, Bierma-Zeinstra SM. Brace treatment for osteoarthritis of the knee: A prospective randomized multicentre trial. Osteoarthritis Cartilage. 2006; 14:777-783. [PubMed: 16563810]

28. Kirkley A, Webster-Bogaert S, Litchfield R, et al. The effect of bracing on varus gonarthrosis. J Bone Joint Surg Am. 1999; 8:539-548. [PubMed: 10225800]

29. Witt C, Brinkhaus B, Jena S, et al. Acupuncture in patients with osteoarthritis of the knee: A randomised trial. Lancet. 2005; 366:136-143. [PubMed: 16005336] 
30. Ezzo J, Hadhazy V, Birch S, et al. Acupuncture for osteoarthritis of the knee: A systematic review. Arthritis Rheum. 2001; 44:819-825. [PubMed: 11315921]

31. Foster NE, Thomas E, Barlas P, et al. Acupuncture as an adjunct to exercise based physiotherapy for osteoarthritis of the knee: Randomised controlled trial. BMJ. 2007; 335:436. [PubMed: 17699546]

32. Bellamy N, Campbell J, Robinson V, Gee T, Bourne R, Wells G. Intraarticular corticosteroid for treatment of osteoarthritis of the knee. Cochrane Database Syst Rev. 2006; 2:CD005328. [PubMed: 16625636]

33. Bjordal JM, Klovning A, Ljunggren AE, Slordal L. Short-term efficacy of pharmacotherapeutic interventions in osteoarthritic knee pain: A meta-analysis of randomised placebo-controlled trials. Eur J Pain. 2007; 11:125-138. [PubMed: 16682240]

34. Arroll B, Goodyear-Smith F. Corticosteroid injections for osteoarthritis of the knee: Meta-analysis. BMJ. 2004; 328:869. [PubMed: 15039276]

35. Ravaud P, Moulinier L, Giraudeau B, et al. Effects of joint lavage and steroid injection in patients with osteoarthritis of the knee: Results of a multicenter, randomized, controlled trial. Arthritis Rheum. 1999; 42:475-482. [PubMed: 10088770]

36. Young L, Katrib A, Cuello C, et al. Effects of intraarticular glucocorticoids on macrophage infiltration and mediators of joint damage in osteoarthritis synovial membranes: Findings in a double-blind, placebo-controlled study. Arthritis Rheum. 2001; 44:343-350. [PubMed: 11229465]

37. Cederlof S, Jonson G. Intraarticular prednisolone injection for osteoarthritis of the knee: A double blind test with placebo. Acta Chir Scand. 1966; 132:532-537. [PubMed: 5339634]

38. Dieppe PA, Sathapatayavongs B, Jones HE, Bacon PA, Ring EF. Intra-articular steroids in osteoarthritis. Rheumatol Rehahil. 1980; 19:212-217.

39. Friedman DM, Moore ME. The efficacy of intraarticular steroids in osteoarthritis: A double-blind study. J Rheumatol. 1980; 7:850-856. [PubMed: 7009857]

40. Gaffney K, Ledingham J, Perry JD. Intraarticular triamcinolone hexacetonide in knee osteoarthritis: Factors influencing the clinical response. Ann Rheum Dis. 1995; 54:379-381. [PubMed: 7794044]

41. Jones A, Doherty M. Intra-articular corticosteroids are effective in osteoarthritis but there are no clinical predictors of response. Ann Rheum Dis. 1996; 55:829-832. [PubMed: 8976640]

42. Miller JH, White J, Norton TH. The value of intra-articular injections in osteoarthritis of the knee. J Bone Joint Surg Br. 1958; 40:636-643. [PubMed: 13610976]

43. Popov VV, Bunchuk NV, Apenysheva NP. Treatment of patients with gonarthrosis by intraarticular administration of drugs. Klin Med (Mosk). 1989; 67:104-108. [PubMed: 2666728]

44. Raynauld JP, Buckland-Wright C, Ward R, et al. Safety and efficacy of long-term intraarticular steroid injections in osteoarthritis of the knee: A randomized, double-blind, placebo-controlled trial. Arthritis Rheum. 2003; 48:370-377. [PubMed: 12571845]

45. Smith MD, Wetherall M, Darby T, et al. A randomized placebo-controlled trial of arthroscopic lavage versus lavage plus intra-articular corticosteroids in the management of symptomatic osteoarthritis of the knee. Rheumatology (Oxford). 2003; 42:1477-1485. [PubMed: 12867587]

46. Wright V, Chandler GN, Morison RA, Hartfall SJ. Intra-articular therapy in osteo-arthritis: Comparison of hydrocortisone acetate and hydrocortisone tertiary- buty lacetate. Ann Rheum Dis. 1960; 19:257-261. [PubMed: 13786828]

47. Bradley JD, Heilman DK, Katz BP, Gsell P, Wallick JE, Brandt KD. Tidal irrigation as treatment for knee osteoarthritis: A sham-controlled, randomized, double-blinded evaluation. Arthritis Rheum. 2002; 46:100-108. [PubMed: 11817581]

48. Chang RW, Falconer J, Stulberg SD, Arnold WJ, Manheim LM, Dyer AR. A randomized, controlled trial of arthroscopic surgery versus closed-needle joint lavage for patients with osteoarthritis of the knee. Arthritis Rheum. 1993; 36:289-296. [PubMed: 8452573]

49. Dawes PT, Kirlew C, Haslock I. Saline washout for knee osteoarthritis: Results of a controlled study. Clin Rheumatol. 1987; 6:61-63. [PubMed: 3581699]

50. Ike RW, Arnold WJ, Rothschild EW, Shaw HL. Tidal irrigation versus conservative medical management in patients with osteoarthritis of the knee: A prospective randomized study. Tidal Irrigation Cooperating Group. J Rheumatol. 1992; 19:772-779. [PubMed: 1613709] 
51. Laupattarakasem W, Laopaiboon M, Laupattarakasem P, Sumananont C. Arthroscopic debridement for knee osteoarthritis. Cochrane Database Syst Rev. 2008; 1:CD005118. [PubMed: 18254069]

52. Hubbard MJ. Articular debridement versus washout for degeneration of the medial femoral condyle: A five-year study. J Bone Joint Surg Br. 1996; 78:217-219. [PubMed: 8666628]

53. Moseley JB, O’Malley K, Petersen NJ, et al. A controlled trial of arthroscopic surgery for osteoarthritis of the knee. N Engl J Med. 2002; 347:81-88. [PubMed: 12110735]

54. Kalunian KC, Moreland LW, Klashman DJ, et al. Visually-guided irrigation in patients with early knee osteoarthritis: A multicenter randomized, controlled trial. Osteoarthritis Cartilage. 2000; 8:412-418. [PubMed: 11069725]

55. Brouwer RW, Raaij van TM, Bierma-Zeinstra SM, Verhagen AP, Jakma TS, Verhaar JA. Osteotomy for treating knee osteoarthritis. Cochrane Database Syst Rev. 2007; 3:004019.

56. W-Dahl A, Toksvig-Larsen S, Roos EM. A 2-year prospective study of patient-relevant outcomes in patients operated on for knee osteoarthritis with tibial osteotomy. BMC Musculoskelet Disord. 2005; 6:18. [PubMed: 15811186]

57. Yasuda K, Majima T, Tanabe Y, Kaneda K. Long-term evaluation of high tibial osteotomy for medial osteoarthritis of the knee. Bull Hosp Jt Dis Orthop Inst. 1991; 51:236-248. [PubMed: 1666012]

58. Devgan A, Marya KM, Kundu ZS, Sangwan SS, Siwach RC. Medial opening wedge high tibial osteotomy for osteoarthritis of knee: Long-term results in 50 knees. Med J Malaysia. 2003; 58:62 68. [PubMed: 14556327]

59. Klinger HM, Lorenz F, Harer T. Open wedge tibial osteotomy by hemicallotasis for medial compartment osteoarthritis. Arch Orthop Trauma Surg. 2001; 121:245-247. [PubMed: 11409551]

60. Naudie D, Bourne RB, Rorabeck CH, Bourne TJ. The Install Award: Survivorship of the high tibial valgus osteotomy: A 10- to -22-year follow-up study. Clin Orthop Relat Res. 1999; 367:1827. [PubMed: 10546594]

61. Myrnerts R. High tibial osteotomy with overcorrection of varus malalignment in medial gonarthrosis. Acta Orthop Scand. 1980; 51:557-560. [PubMed: 7446041]

62. Stukenborg-Colsman C, Wirth CJ, Lazovic D, Wefer A. High tibial osteotomy versus unicompartmental joint replacement in unicompartmental knee joint osteoarthritis: 7-10-year follow-up prospective randomised study. Knee. 2001; 8:187-194. [PubMed: 11706726]

63. Brouwer RW, Bierma-Zeinstra SM, van Raaij TM, Verhaar JA. Osteotomy for medial compartment arthritis of the knee using a closing wedge or an opening wedge controlled by a Puddu plate: A one-year randomised, controlled study. J Bone Joint Surg Br. 2006; 88:1454-1459. [PubMed: 17075089]

64. Adili A, Bhandari M, Giffin R, Whately C, Kwok DC. Valgus high tibial osteotomy: Comparison between an Ilizarov and a Coventry wedge technique for the treatment of medial compartment osteoarthritis of the knee. Knee Surg Sports Traumatol Arthrosc. 2002; 10:169-176. [PubMed: 12012035]

65. Magyar G, Ahl TL, Vibe P, Toksvig-Larsen S, Lindstrand A. Open-wedge osteotomy by hemicallotasis or the closed-wedge technique for osteoarthritis of the knee: A randomised study of 50 operations. J Bone Joint Surg Br. 1999; 81:444-448. [PubMed: 10872363]

66. Hoell S, Suttmoeller J, Stoll V, Fuchs S, Gosheger G. The high tibial osteotomy, open versus closed wedge, a comparison of methods in 108 patients. Arch Orthop Trauma Surg. 2005; 125:638-643. [PubMed: 16133475]

67. Sisto DJ, Mitchell IL. UniSpacer arthroplasty of the knee. J Bone Joint Surg Am. 2005; 87:17061711. [PubMed: 16085608]

68. Australian Orthopaedic Association National Joint Replacement Registry . Annual Report. Adelaide, SA, Australia: 2004. Available at: http://www.dmac.adelaide.edu.au/aoanjrr/documents/aoanjrrreport_2004.pdf

69. Joint Replacement Registry. Annual Report. Adelaide, SA, Australia: 2005. Available at: http://www.dmac.adelaide.edu.au/aoanjrr/documents/aoanjrrreport_2005.pdf

70. Joint Replacement Registry. Annual Report. Adelaide, SA, Australia: 2006. Available at: http://www.dmac.adelaide.edu.au/aoanjrr/documents/aoanjrrreport_2006.pdf 
71. Joint Replacement Registry . Annual Report. Adelaide, SA, Australia: 2007. Available at: http://www.dmac.adelaide.edu.au/aoanjrr/documents/aoanjrrreport_2007.pdf 